\title{
Seed production from the mixed mating system of Chesapeake Bay (USA) eelgrass (Zostera marina; Zosteraceae)
}

JM Rhode

Virginia Institute of Marine Science

JE Duffy

Virginia Institute of Marine Science

Follow this and additional works at: https://scholarworks.wm.edu/vimsarticles

Part of the Marine Biology Commons

\section{Recommended Citation}

Rhode, JM and Duffy, JE, "Seed production from the mixed mating system of Chesapeake Bay (USA) eelgrass (Zostera marina; Zosteraceae)" (2004). VIMS Articles. 1643.

https://scholarworks.wm.edu/vimsarticles/1643 


\title{
SEED PRODUCTION FROM THE MIXED MATING SYSTEM OF Chesapeake BAy (USA) eelgrass (ZoSTERA MARINA; ZOSTERACEAE) ${ }^{1}$
}

\author{
JENNIFER M. RHODE² AND J. EMMETT DUFFY \\ College of William and Mary, School of Marine Science, P.O. Box 1346, Gloucester Point, Virginia 23062 USA
}

\begin{abstract}
In monoecious plants, gametes can be exchanged in three ways: among unrelated genets (outbreeding), with close relatives (inbreeding), or within individuals (geitonogamous selfing). These different mating systems may have consequences for population demography and fitness. The experiment presented herein used artificial crosses to examine the mating system of Chesapeake Bay, Virginia, USA eelgrass (Zostera marina L; Zosteraceae), a bisexual submerged aquatic plant that can outbreed, inbreed, and self. Genetic data indicate severe heterozygosity deficiencies and patchy genotype distribution in these beds, suggesting that plants therein reproduce primarily by vegetative propagation, autogamy, or geitonogamy. To clarify eelgrass reproductive strategies, flowers from three genetically and geographically distinct beds were hand-pollinated in outbred, inbred, and selfed matings. Fertilization success and seed production, life history stages which contribute greatly to the numeric maintenance of populations, were monitored. We found no evidence that inbreeding had negative consequences for seed production. On the contrary, selfed matings produced seeds significantly more frequently than outcrossed matings and produced significantly larger numbers of seeds than either inbred or outbred matings. These results contrast with patterns for eelgrass in other regions but might be expected for similar populations in which pollen limitation or a short reproductive season renders selfing advantageous.
\end{abstract}

Key words: inbreeding; mating system; outbreeding; reproductive assurance; seed production; self-fertilization; Zosteraceae; Zostera marina.

Plant mating systems range from outbreeding among unrelated individuals to inbreeding among relatives and self-fertilization (Shields, 1993; Waser, 1993b). The continuum of angiosperm mating strategies corresponds to a range of consequences for the ecology and evolution of flowering plant populations. Outbreeding tends to homogenize population genetic structure and can increase overall genetic diversity (Waser, 1993a). Conversely, outbreeding can result in the break-up of multi-locus genotypes and disruption of local adaptation, leading to reduced offspring fitness (outbreeding depression) (e.g., Montalvo and Ellstrand, 2001). Though outbreeding depression has been demonstrated via artificial matings for several terrestrial plant species, it seems to occur less frequently than inbreeding depression (reviewed in Waller [1993] and Waser [1993a]). At the other extreme of the mating continuum, selffertilization maximizes the parent's genetic contribution to its offspring and avoids recombination with poorly adapted genotypes. However, offspring produced by selfed matings often experience inbreeding depression, indicated by reduced heterozygosity and the expression of deleterious mutations (reviewed in Waller [1993] and Waser [1993a]). Self-fertilization is rarely the most fit plant mating strategy, but it provides reproductive assurance while retaining a mechanism for outbreeding (Waser, 1993b).

Eelgrass (Zostera marina L.; Zosteraceae), the Northern

\footnotetext{
${ }^{1}$ Manuscript received 11 March 2003; revision accepted 11 September 2003.

The authors thank R. J. Orth and K. A. Moore for greenhouse space and equipment; M. B. Cruzan, M. C. Harwell, A. P. Ramakrishnan, K. R. Reece, and S. L. Williams for comments on this manuscript; and the National Science Foundation (pre-doctoral fellowship to J. M. R.), Virginia Institute of Marine Science, and the College of William and Mary/School of Marine Science for funding. This is contribution \# 2567 from the Virginia Institute of Marine Science.

${ }^{2}$ Current address: Department of Biology, Portland State University, P.O. Box 751 Portland, Oregon 97207 USA. E-mail: jmrhode@pdx.edu.
}

hemisphere's most common temperate marine angiosperm (den Hartog, 1970), displays a full range of reproductive strategies and is thus an ideal plant for mating system studies. It grows clonally, and populations usually consist of many genetically identical shoots (ramets) that form large interconnected or fragmented genetic individuals (genets). Zostera marina is monoecious, with female and male flowers on a single inflorescence, so genetic exchange might occur within individual ramets as well as within and among populations (Ruckelshaus, 1995). Flowering shoots and the inflorescences they bear mature from the bottom up (acropetally), and flowers on a single inflorescence emerge asynchronously, with stigmas maturing first (protogyny) and pollen released $48 \mathrm{~h}$ later (de Cock, 1980). Thus, while self-fertilization within eelgrass inflorescences in nature is probably rare, flowering is not coordinated among ramets, so geitonogamy (self-fertilization among inflorescences on different ramets of the same genet) probably occurs (Reusch, 2001). Vegetative expansion of eelgrass patches is rapid (Olesen and Sand-Jensen, 1994a, b), seed production is unpredictable in both space and time (Silberhorn et al., 1983; van Lent and Verschuure, 1995; MelingLopez and Ibarra-Obando, 1999), and mortality of eelgrass seeds (Fishman and Orth, 1996; Orth et al., 2000) and seedlings (Hootsmans et al., 1987) can exceed $90 \%$.

Because eelgrass flowering tends towards protogyny, previous research assumed that most seeds were produced by outbreeding (Setchell, 1929; de Cock, 1980; Phillips et al., 1983). Genetic and breeding studies of European and Washington, USA, populations demonstrated that self-fertilization is possible but occurs infrequently. Hand pollination produced some inbred seeds (Cox et al., 1992; Ruckelshaus, 1995), and a microsatellite survey by Reusch (2001) indicated that many seeds from two Baltic Sea populations were produced by geitonogamy. However, most seedlings and adults in manipulated and natural populations were produced by outcrossing (Ruckel- 
shaus, 1994; Reusch, 2000, 2001). Allozyme and molecular studies revealed high inbreeding coefficients within many beds, but the relative fitness of offspring produced by geitonogamy or inbreeding was low compared to outbred progeny (Ruckelshaus, 1995; Reusch, 2000, 2001). The geographic and ecological range of Zostera marina is vast (Phillips et al., 1983), however, and eelgrass mating systems might vary with environment or region.

Eelgrass populations in Chesapeake Bay, USA, occupy the southern limit of their biogeographic range, and they are dramatically different from their counterparts in Europe and other parts of North America. In the Baltic Sea, a relatively stable environment, eelgrass clones are large and persistent (Reusch et al., 1999a, b; Reusch, 2000). Chesapeake Bay populations, conversely, are demographically dynamic, and their life cycle includes summer defoliation and dieback (Orth and Moore, 1986). Clones seem to be much smaller, with beds less than 5 ha consisting of at least 12 genetic individuals (estimated from allozymes; Rhode, 2002). An allozyme survey of 12 geographically and morphologically variable Chesapeake Bay eelgrass beds displayed significant levels of inbreeding (mean $F_{\text {IS }}=$ 0.68 over all beds). Genetic diversity within beds was high, and beds showed strong genetic differentiation over relatively short distances $\left(F_{\mathrm{ST}}=0.198\right)$ (Rhode, 2002). It seems reasonable, then, to expect fairly regular inbreeding in Chesapeake Bay eelgrass, at the extreme of $Z$. marina's geographic distribution. Chesapeake Bay eelgrass might also be inferred to inbreed because heterozygosity levels are relatively low $(H=$ $0.38-0.48$ over seven allozyme loci in the three beds studied), and beds show significant levels of Hardy-Weinberg disequilibrium (heterozygote deficiencies; $P<0.0001$ for all beds) (Williams and Orth, 1998). Though Puget Sound (Washington, USA) eelgrass is locally adapted for some traits (Ruckelshaus, 1994), a year-long reciprocal transplant experiment using four Chesapeake Bay populations found little evidence of local adaptation in vegetative or sexual fitness characters (Rhode, 2002).

As a follow-up to the genetic survey of Rhode (2002), this study used hand pollinations to determine potential variation in and consequences of different mating patterns for eelgrass populations in Chesapeake Bay. Controlled crosses were employed to complement the previous study using neutral genetic markers (Rhode, 2002) as we wanted to explore the range of potential breeding systems in these plants. We used these experiments to compare fertilization success and seed production among selfed, inbred, and outcrossed matings. We chose to focus on this life history stage as seeds are critical to establishment and maintenance of these eelgrass populations (Orth et al., 2003; R. Orth, College of William and Mary School of Marine Science, unpublished data). If populations typically outbreed, as Baltic Sea Zostera marina does (Reusch, 2000), inbreeding depression should be manifest in this early life stage (Husband and Schemske, 1996).

\section{MATERIALS AND METHODS}

For the purposes of this experiment, selfed matings are those that occurred among different plants of the same genet. Since among-bed genetic and morphological diversity is high in Chesapeake Bay eelgrass (Rhode, 2002) and movement of viable pollen between beds is probably uncommon (Ruckelshaus, 1994), intrabed matings were considered inbred. For the same reasons, interbed matings were considered outbred. To determine seed production from different mating systems of Chesapeake Bay (Virginia, USA; $37^{\circ} \mathrm{N}, 76^{\circ} \mathrm{W}$ ) Zostera marina, controlled laboratory pollinations were conducted among in- dividuals from three geographically, morphologically, and genetically different beds (Rhode, 2002): Allen's Island, Brown's Bay, and Broad Bay (Fig. 1). Allen's Island and Brown's Bay are geographically proximate and might be expected to have regular propagule exchange, while Broad Bay is more isolated but has a much lower inbreeding coefficient $\left(F_{\text {IS }}\right)$ (Rhode, 2002). Plants from Allen's Island and Broad Bay are significantly longer and wider than those from Brown's Bay, but shoot density in Brown's Bay is significantly higher than in the other two sites. Plants in Broad Bay are significantly less inbred than the other two beds, but other estimates of genetic diversity do not differ among the sites. In natural populations, seed production by Broad Bay plants is significantly lower than that from the other two beds (Rhode, 2002).

In spring (April) 1998, 140 reproductive shoots were collected at haphazard locations within each of the three sites. Each reproductive shoot was collected with an attached vegetative shoot to provide a source of photosynthate for its developing flowers and seeds. Distance between collection spots exceeded 2 $\mathrm{m}$ to minimize resampling of single genets (as in Ruckelshaus, 1994). Shoots were transported to a greenhouse, where they were tagged to identify the site of origin. Each shoot was then planted in a $20 \mathrm{~cm}$ high plastic pot filled with native sediment and placed in outdoor flow-through estuarine water tanks. To simulate field conditions, tanks contained water $0.6 \mathrm{~m}$ deep and were shaded to $40 \%$ ambient light. Water temperatures were warmer than ambient, so emergence of flowers was more rapid and frequent than in field populations. Approximately $2 \mathrm{~d}$ before pistil emergence (de Cock, 1980), maturing inflorescences were encased in $0.25 \mathrm{~mm}^{2}$ mesh bags to prevent unplanned pollinations.

Eelgrass flowers mature over a 2-4 wk period (de Cock, 1980). During this time, inflorescences were checked for maturation status every 6-8 h. Shoots with receptive stigmas were moved from the large holding tank to a small, flow-free aquarium for controlled crosses. A pollen donor was randomly chosen from one of the three treatments (different bed, same bed, or same individual), and forceps were used to remove a single male flower. For selfed matings, pollen from another inflorescence on the same individual was used. Pollen strands were separated until they floated at the water's surface, and strands were draped across three receptive stigmas per inflorescence for 10 min (following Ruckelshaus, 1994), enough time for a pollen tube to begin growing (J. M. Rhode, personal observation). The mesh bag was then replaced, and the plant containing the manipulated female flower was returned to the larger holding tank. A total of 20 crosses for each combination were attempted. Logistical constraints, including the short window of time during which flowering shoots were available and the difficulty of achieving flowering synchronicity, prevented further replication.

When stigmata senesced and were no longer receptive (1-3 d after pollination), each fertilized inflorescence was unbagged and monitored for seed development. Ten days after senescence, numbers of viable seeds per shoot were counted; seeds with intact coats and firm endosperm were scored as viable (Harrison, 1991). Care was taken to ensure that all crosses were done using flowers of the same age and that pollen handling was consistent. Plants that died before setting seed or whose prefertilization history was unknown were not used in the final analysis. Neither pollen donors nor receptive inflorescences were used for more than one cross, rendering all crosses and treatments independent.

To maximize sample size, experiments were repeated in 1999 using plants from the same beds. Nonparametric ANOVA revealed no effects of year or of year by treatment interaction (Mann-Whitney; $P>0.05$ for each) on the success of crosses or on subsequent seed production (SAS, 1999). Therefore, data from 1998 and 1999 were pooled for further analysis.

Overall sample sizes were sufficient for hypothesis testing but were relatively small and varied among treatments $(N=5-21$ per specific cross; 3544 per cross category). Therefore, differences in mating success (binary: seed produced or not) and seed production (number of seeds from three potentially fertilized stigmata) among the three cross types (interbed, intrabed, and selfed) were determined by resampling analysis in Excel (Blank et al., 1999). We tested the three possible comparisons for each response variable: outbred vs. inbred, outbred vs. selfed, and inbred vs. selfed. For each comparison, the data matrix was resampled with replacement $1 \times 10^{4}$ times, and the difference 


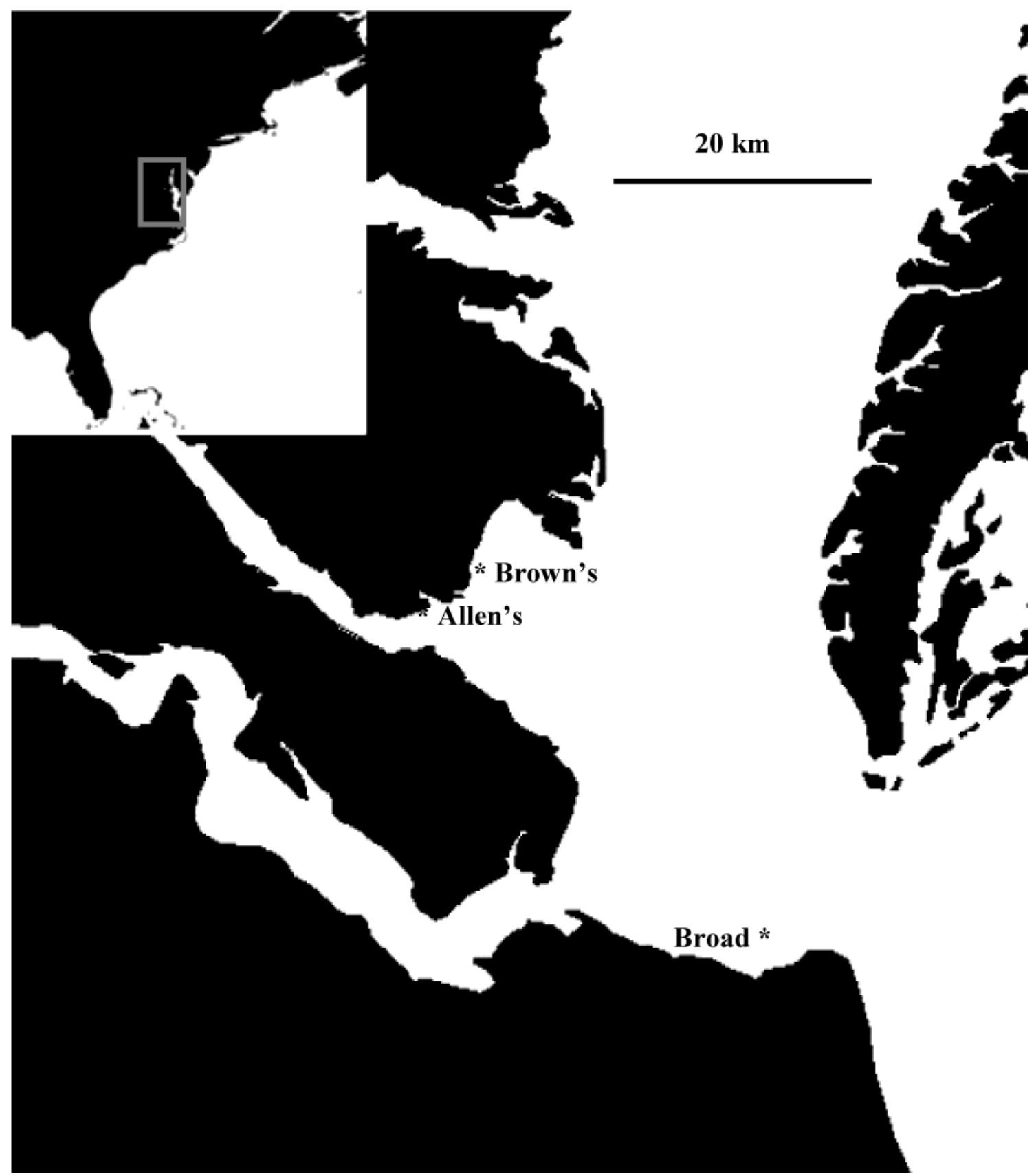

Fig. 1. Map of southern Chesapeake Bay, Virginia, USA. Sites from which plants for artificial crosses were taken are labeled.

between mating type means was calculated for each resampling run. The observed difference between means was then compared to the distribution of resampled values to calculate the probability of obtaining the observed value by chance alone. Because three pairs of means were compared using the resampling analyses, a $P$ value of $0.05 / 3$, or 0.0167 , was used as the critical value for statistical significance.

\section{RESULTS}

In these greenhouse experiments, $37 \%$ of all crosses produced seeds. This success rate was lower than seed sets from a natural field population (72\%; Churchill and Riner, 1978) and from another hand-pollination experiment (67\%; Ruckel- shaus, 1995). All types of matings produced at least some seeds, though.

We found a significant effect of maternal source on percent successful crosses (Kruskal-Wallis; $N=25, P=0.0327$ ). Maternal effects were significant for Broad Bay only, where values for both fertilization success (seed/no seed) and seed production (number of seeds) were lower than for Allen's Island or Brown's Bay, regardless of mating treatment. No paternal effects were found in any mating, as pollen source did not affect the success of fertilization (Kruskal-Wallis; $N=25, P$ $=0.7604$ ) or the number of seeds produced (Kruskal-Wallis; $N=25, P=0.4849$ ). In further analyses, therefore, data were pooled for all maternal/paternal source combinations within a 


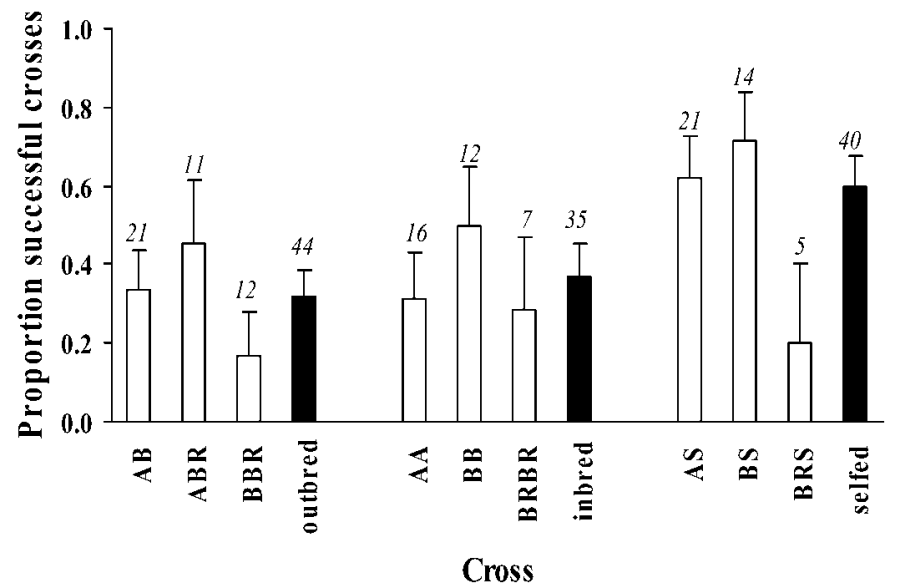

Fig. 2. Proportion of crosses that produced viable seeds in outbred, inbred, and selfed matings (means $\pm 1 \mathrm{SE}$ ). Letters beneath bars indicate pollen and ovule donors for each cross. A = Allen's Island, B = Brown's Bay, and BR = Broad Bay; means for each cross type are also shown. Overall $N=35$ 44 per cross type. Number above bar is actual $N$ per specific cross.

treatment of outbred, inbred, and selfed crosses. Treatment effects remained significant whether or not crosses with Broad Bay mothers were excluded.

Mating type significantly affected the proportion of crosses that produced viable seeds (Fig. 2). Resampling analysis showed that the ability to produce any seed was significantly greater in selfed crosses than in outbred crosses $(P=0.0130)$; no other paired comparisons were statistically significant at the critical $P=0.0167$ level (selfed vs. inbred, $P=0.0420$; inbred vs. outbred, $P=0.6440$; Fig. 2). Mating treatment also influenced number of seeds produced per cross (Fig. 3). Selfed matings produced $80 \%$ more viable seeds per pollination than inbred matings, a significant effect $(P=0.0137)$, and more than twice as many seeds as outbred matings $(P=0.0004)$. There was no difference in number of seeds produced by inbred vs. outbred crosses $(P=0.2360)$.

\section{DISCUSSION}

Results of our breeding experiments indicate no absolute genetic barrier to outcrossed, inbred, or selfed matings in Zostera marina from three morphologically and genetically diverse Chesapeake Bay beds. This finding is consistent with the results of artificial matings and of field surveys in other eelgrass populations (Ruckelshaus, 1994; Reusch, 2001). In nature, geitonogamous matings might occur, but Chesapeake Bay clones are small relative to their European counterparts, so this form of selfing might be less common in Chesapeake Bay. At the other mating extreme, limited pollen dispersal (on a scale of tens of meters; Ruckelshaus, 1994) probably renders outbred crosses very infrequent.

Self-fertilizations of Chesapeake Bay eelgrass produced more seeds than either inbreeding or outbreeding, indeed exceeding the number of seeds from outbred crosses by a factor of 2.7 (Fig. 3). This novel finding supports field genetic data, which indicate extremely localized breeding and strong heterozygote deficiencies in these beds (Rhode, 2002). Although eelgrass is protogynous, a trait usually associated with inbreeding depression, it can produce seeds via selfing if flowering asynchrony is overcome artificially, through intraflorescence flowering synchronicity (rare in nature; J. M. Rhode, personal

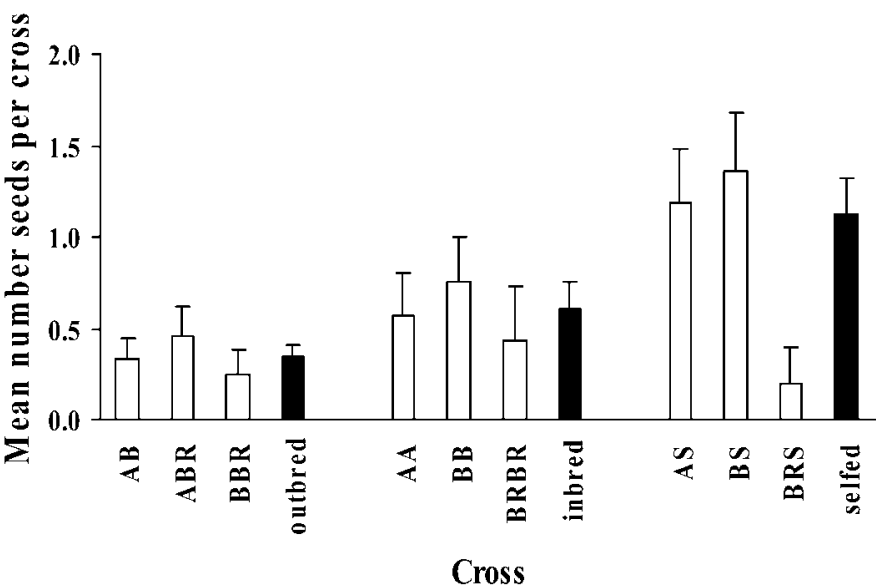

Fig. 3. Numbers of seeds (of three possible) produced per cross in outbred, inbred, and selfed matings (means $\pm 1 \mathrm{SE}$ ). Symbols as in Fig. 2.

observation) or geitonogamy. Most studies of plants with mixed mating systems have demonstrated that self-fertilization produces fewer seeds and offspring of lower fitness than outbreeding (reviewed in Waser [1993b]). Chesapeake Bay eelgrass seems to be an exception to this generality, but it resembles other plant populations with limited life spans or restricted windows of reproduction (Parker et al., 1995; Eckert and Schaefer, 1998). In fact, the mating system of the Chesapeake Bay eelgrass beds we studied is more typical of a plant adapted to self-fertilization. Like other selfing plants (Schoen and Brown, 1991), Chesapeake Bay eelgrass populations display a wide range of genetic diversity. The difference between selfing rates in eelgrass from Chesapeake Bay vs. other regions might be due to increased selfing at the edge of $Z$. marina's range. This has been observed at the edge of other plant ranges (Barrett and Husband, 1990) and in areas where species are colonizers (Barrett and Richardson, 1986).

Seed production was significantly lower in mothers from Broad Bay compared with the other two sites. Field monitoring data show that Broad Bay plants have much lower seed set than other Chesapeake Bay beds (Rhode, 2002), so intrinsic factors might make them poor seed parents. It is interesting to note that inbreeding coefficients in Broad Bay plants are much lower than for other beds (Rhode, 2002), despite Broad Bay plants producing a relatively high number of seeds from selfed matings (Fig. 3). This discrepancy between the apparent field mating system and the potential mating system revealed by the breeding study suggests that demographic factors have a great influence on field mating systems in Chesapeake Bay eelgrass.

Although self-fertilization was the most successful type of mating in this greenhouse study, and allozyme data show strong heterozygote deficiencies consistent with some degree of inbreeding (Rhode, 2002), allozyme data also show high levels of genetic diversity within beds (Rhode, 2002). This diversity is likely maintained by regular mating among the relatively small eelgrass clones that make up Chesapeake Bay beds. Genetic diversity may also be augmented by seeds imported from other beds via rafting reproductive shoots (Harwell and Orth, 2002). However, the strong genetic subdivision among beds (Rhode, 2002) suggests that such dispersing seeds contribute little to the demography of the recipient beds. Finally, it should be noted that genetic differentiation among sites is not accompanied by strong local adaptation in Chesa- 
peake Bay eelgrass, as evidenced by a year-long reciprocal transplant study (Rhode, 2002). Therefore, the fate of seeds (i.e., whether they are transported to an environment suitable for germination) seems far more important than their origin.

In our experiments, neither crossing success nor seed production showed any evidence of the inbreeding disadvantage demonstrated in other eelgrass populations (Ruckelshaus, 1994; Reusch, 2001). Seed set from inbred (within-bed) and outbred (between-bed) matings was comparable, possibly because genetic diversity within beds is only slightly higher than that among beds in these populations (Rhode, 2002); partners from the opposite side of a bed or the opposite side of Chesapeake Bay might be similarly genetically distant from the parent. In addition, all inter- and most intrabed distances were greater than the range of successful pollen movement. This, coupled with pollen dispersal distances that were orders of magnitude smaller than bed sizes, might have rendered inbred and outbred matings demographically comparable. In a study of another aquatic angiosperm, Waycott and Sampson (1997) suggested that mating systems were determined in part by pollen travel distances.

Plants that self-fertilize regularly are usually either annuals or biennials whose temporal window for reproductive success might be limited (Aarssen, 2000), as selfing can be advantageous for plants whose density is low or whose pollen supply is uncertain (Darwin, 1876; Baker, 1955; Barrett, 1988; Larson and Barrett, 2000). In the eelgrass beds we studied, self-fertilization might thus be a mechanism for reproductive assurance. Chesapeake eelgrass plants do not achieve sexual maturity until their second year and probably are not long-lived (Harwell, 2000). Moreover, Chesapeake Bay beds frequently experience a die-off in late summer. Thus, annual numbers of mature individuals might fluctuate widely, and eelgrass distribution is patchy (Orth et al., 1998). Because Chesapeake Bay eelgrass beds are smaller and patchier than their European or eastern Pacific counterparts, self-fertilization might also provide reproductive assurance in the face of limited pollen dispersal and availability (Jain, 1976). Eelgrass pollen is viable for less than $8 \mathrm{~h}$ and is easily snared on other objects in the water (de Cock, 1980; J. M. Rhode, personal observation). A recent survey found that $62 \%$ of angiosperms tested showed some spatial or temporal pollen limitation (Burd, 1994), and this seems to be true for eelgrass as well (Ruckelshaus, 1996). Surveys of natural populations to determine seed parentage will be an interesting follow-up to this greenhouse study.

One caveat to this work is that fitness measurements were made at only a single point in the organism's life history (seed set). While this seems to be the most important life history stage for population growth and maintenance, the relative contributions to fitness of seedling production and adult shoot growth are unknown for our populations. Selection at later stages (germination or seedling survival) might reduce the fitness of seeds produced through selfing. In fact, a review by Husband and Schemske (1996) found that most selfing species expressed inbreeding depression in post-germination stages of life history; studies of eelgrass in other systems support this finding (Ruckelshaus, 1994; Reusch, 2001). Phillips et al. (1983) predicted that seeds were the most important eelgrass life history stage during which selection could act, and Ruckelshaus $(1994,1995)$ found that inbreeding depression was usually expressed as differential germination success rather than seed set. Thus, it is possible that inbreeding depression occurs at later life stages in Chesapeake Bay eelgrass. Nev- ertheless, it is noteworthy that selfed matings produced almost three times as many seeds as outbred matings (Fig. 3), which contrasts markedly with previous findings for other eelgrass populations (Ruckelshaus, 1995). This suggests a real difference in mating strategies among eelgrass populations. Although we did not test explicitly for germination differences among mating types, reciprocal transplant experiments (Rhode, 2002) did provide evidence of interpopulation variation in germination success of in situ-produced seeds. However, given the significant deficiency of heterozygotes and levels of inbreeding in Chesapeake Bay eelgrass, it is probable that selfed seeds are indeed produced in situ and contribute to population genetic structure of these beds.

If the seed parentage effects seen here are present in field populations, they might influence bed persistence and expansion. Seeds are produced in large numbers and contribute to eelgrass bed maintenance and colonization (Olesen and SandJensen, 1994b). This might be especially important in Chesapeake Bay, which experiences frequent disturbances from storms, dredging, bioturbation, and seasonal senescence (Orth and Moore, 1986). Reusch (2001) found that seeds from geitonogamous matings were underrepresented in the adult eelgrass population, and he attributed this to selection against selfed seeds and the resultant inbreeding depression. Another possible outcome is that repeated selfing lets populations purge deleterious mutations, allowing the selfing mating strategy to persist (Morgan et al., 1997). We found no evidence of inbreeding depression or reduced genetic diversity in Chesapeake Bay eelgrass and indeed found that selfed matings produced many more seeds than outbred matings. Thus, our results suggest that there is little or no endogenous selection against selfing in these beds and that selfing may even be advantageous in Chesapeake Bay eelgrass.

\section{LITERATURE CITED}

AARsSEn, L. W. 2000. Why are most selfers annuals? A new hypothesis for the fitness benefit of selfing. Oikos 89: 606-612.

BAKER, H. G. 1955. Self-compatibility and establishment after "long-distance" dispersal. Evolution 9: 347-348.

BARRETT, S. C. H. 1988. The evolution, maintenance and loss of self-incompatibility systems. In J. L. Doust and L. L. Doust [eds.], Plant reproductive ecology. Oxford University Press, New York, New York, USA.

BARRETT, S. C. H., AND B. Husband. 1990. The genetics of plant migration and colonization. In A. H. D. Brown, M. T. Clegg, A. L. Kahler, and B. S. Weir [eds.], Plant population genetics, breeding, and genetic resources, 254-277. Sinauer, Sunderland, Massachusetts, USA.

BARRETt, S. C. H., AND B. J. Richardson. 1986. Genetic attributes of invading species. In R. H. Groves and J. J. Burdon [eds.], Ecology of biological invasions: an Australian perspective, 21-33. Australian Academy of Science, Canberra, Australian Capital Territory, Australia.

Blank, S., C. Seiter, and P. Bruce. 1999. Resampling stats in Excel, version 1.1. Resampling Stats, Arlington, Virginia, USA.

BuRD, M. 1994. Bateman's principle and plant reproduction: the role of pollen limitation in fruit and seed set. Botanical Review 60: 83-139.

Charlesworth, D., AND B. Charlesworth. 1987. Inbreeding depression and its evolutionary consequences. Annual Review of Ecology and Systematics 18: 237-268.

Churchill, A. C., AND M. I. Riner. 1978. Anthesis and seed production in Zostera marina L. from Great South Bay, New York, U.S. Aquatic Botany 4: 83-93.

Cox, P. A., R. H. Laushman, and M. Ruckelshaus. 1992. Surface and submarine pollination in the seagrass Zostera marina L. Botanical Journal of the Linnaean Society 109: 281-291.

DARwin, C. R. 1876. The effects of cross and self-fertilization in the vegetable kingdom. John Murray, London, UK.

DE COCK, A. W. 1980. Flowering, pollination, and fruiting in Zostera marina L. Aquatic Botany 9: 202-220. 
DEN HaRToG, C. 1970. Seagrasses of the world. North-Holland, Amsterdam, The Netherlands.

ECKERT, C. G., AND A. SCHAEFER. 1998. Does self-pollination provide reproductive assurance in Aquilegia canadensis (Ranunculaceae)? American Journal of Botany 85: 919-924.

Fishman, J. R., AND R. J. ORTH. 1996. Effects of predation on Zostera marina L. seed abundance. Journal of Experimental Marine Biology and Ecology 198: 11-26.

HARrison, P. G. 1991. Mechanisms of seed dormancy in an annual population of Zostera marina (eelgrass) from the Netherlands. Canadian Journal of Botany 69: 1972-1976.

HARWELL, M. C. 2000. Ecological dispersal mechanisms, reproductive ecology, and the importance of scale in Zostera marina in Chesapeake Bay. Ph.D. dissertation, Virginia Institute of Marine Science, College of William and Mary, Gloucester Point, Virginia, USA.

Harwell, M. C., AND R. J. ORTH. 2002. Long-distance dispersal potential in a marine macrophyte. Ecology 83: 3319-3330.

Hootsmans, M. J. M., J. E. VermaAt, and W. Van Vierssen. 1987. Seedbank development, germination, and early seedling survival of two seagrass species from the Netherlands: Zostera marina L. and Zostera noltii Hornem. Aquatic Botany 28: 275-285.

Husband, B. C., AND D. W. SCHEMSKE. 1996. Evolution of the magnitude and timing of inbreeding depression in plants. Evolution 501: 54-70.

JAIN, S. K. 1976. The evolution of inbreeding in plants. Annual Review of Ecology and Systematics 7: 69-95.

LARson, B. M. H., AND S. C. H. BARretT. 2000. A comparative analysis of pollen limitation in flowering plants. Biological Journal of the Linnean Society 69: 503-520.

Meling-LopeZ, A. E., And S. E. Ibarra-Obando. 1999. Annual life cycles of two Zostera marina L. populations in the Gulf of California: contrasts in seasonality and reproductive effort. Aquatic Botany 65: 59-69.

Montalvo, A. M., And N. C. Ellstrand. 2001. Nonlocal transplant and outcrossing depression in the sub-shrub Lotus scoparius (Fabaceae). American Journal of Botany 88: 258-269.

Morgan, M. T., D. J. Schoen, And T. M. Bataillon. 1997. The evolution of self-fertilization in perennials. American Naturalist 150: 618-638.

Olesen, B., AND K. SAND-Jensen. 1994a. Demography of shallow eelgrass (Zostera marina) populations - shoot dynamics and biomass development. Journal of Ecology 82: 379-390.

Olesen, B., AND K. SAND-Jensen. 1994b. Patch dynamics of eelgrass, Zostera marina. Marine Ecology Progress Series 106: 147-156.

Orth, R. J., J. R. Fishman, AND M. C. HARwELl. 2003. Seed density effects on germination and initial seedling survival in eelgrass, Zostera marina. Marine Ecology Progress Series 250: 71-79.

Orth, R. J., M. C. Harwell, E. M. Bailey, J. T. Jawad, A. V. Lombana, K. A. Moore, J. M. Rhode, And H. E. Woods. 2000. A review of issues in seagrass seed dormancy and germination: implications for conservation and restoration. Marine Ecology Progress Series 200: 277-288.

Orth, R. J., AND K. A. Moore. 1986. Seasonal and year-to-year variations in the growth of Zostera marina L (eelgrass) in the lower Chesapeake Bay. Aquatic Botany 24: 335-341.

Orth, R. J., J. F. NowaK, D. J. Wilcox, J. R. Whiting, and L. S. Nagey. 1998. Distribution of submerged aquatic vegetation in Chesapeake Bay. U.S. EPA Report, Grant CB993267-03-1, Chesapeake Foundation, Annapolis, Maryland, USA.

PARKer, I. M., R. R. NAKAmURA, AND D. W. Schemske. 1995. Reproductive allocation and the fitness consequences of selfing in two sympatric spe- cies of Epilobium (Onagraceae) with contrasting mating systems. American Journal of Botany 82: 1007-1016.

Phillips, R. C., W. S. GRAnT, AND C. P. McRoy. 1983. Reproductive strategies of eelgrass (Zostera marina L.). Aquatic Botany 16: 1-20.

REusCH, T. B. H. 2000. Pollination in the marine realm: microsatellites reveal high outcrossing rates and multiple paternity in eelgrass Zostera marina. Heredity 85: 459-464.

Reusch, T. B. H. 2001. Fitness-consequences of geitonogamous selfing in a clonal marine angiosperm (Zostera marina). Journal of Evolutionary Biology 14: 129-138.

Reusch, T. B. H., W. T. Stam, and J. L. Olsen. 1999a. Size and estimated age of genets in eelgrass, Zostera marina, assessed with microsatellite markers. Marine Biology 133: 519-525.

Reusch, T. B. H., W. T. Stam, And J. L. Olsen. 1999b. Microsatellite loci in eelgrass Zostera marina reveal marked polymorphism within and among populations. Molecular Ecology 8: 317-321.

Rhode, J. M. 2002. Microevolution in Chesapeake Bay populations of eelgrass (Zostera marina L). Ph.D. dissertation, Virginia Institute of Marine Science, College of William and Mary, Gloucester Point, Virginia, USA.

RucKelshaus, M. H. 1994. Ecological and genetic factors affecting population structure in the marine angiosperm Zostera marina L. Ph.D. dissertation, University of Washington, Seattle, Washington, USA.

RuCKELSHAus, M. H. 1995. Estimates of outcrossing rates and of inbreeding depression in a population of the marine angiosperm Zostera marina. Marine Biology 123: 583-593.

RuCKELSHAUs, M. H. 1996. Estimation of genetic neighborhood parameters from pollen and seed dispersal in the marine angiosperm Zostera marina L. Evolution 50: 856-864.

SAS 1999. Statistical analysis software (SAS). Version 8. SAS Institute, Cary, North Carolina, USA.

SCHOEN, D. J., AND A. H. D. BROWN. 1991. Intraspecific variation in population gene diversity and effective population size correlated with the mating system in plants. Proceedings of the National Academy of Sciences USA 88: 4494-4497.

Setchell, W. A. 1929. Morphological and phenological notes on Zostera marina L. University of California Publications in Botany 14: 389-452.

SHIELDS, W. M. 1993. The natural and unnatural history of inbreeding and outbreeding. In N. M. Thornhill [ed.], The natural history of inbreeding and outbreeding. University of Chicago Press, Chicago, Illinois, USA

Silberhorn, G. M., R. J. Orth, AND K. A. Moore. 1983. Anthesis and seed production in Zostera marina L. (eelgrass) from the Chesapeake Bay. Aquatic Botany 15: 133-144.

VAN LENT, F., AND J. M. VerschuURE. 1995. Comparative study on populations of Zostera marina L. (eelgrass): experimental germination and growth. Journal of Experimental Marine Biology and Ecology 185: 7791.

WASER, N. M. 1993a. Population structure, optimal outbreeding, and assortative mating in angiosperms. In N. M. Thornhill [ed.], The natural history of inbreeding and outbreeding. University of Chicago Press, Chicago, Illinois, USA.

WASER, N. M. 1993b. Sex, mating systems, inbreeding, and outbreeding. In N. M. Thornhill [ed.], The natural history of inbreeding and outbreeding. University of Chicago Press, Chicago, Illinois, USA.

WAyCOTT, M., AND J. F. SAMPSON. 1997. The mating system of an hydrophilous angiosperm Posidonia australis (Posidoniaceae). American Journal of Botany 84: 621-625.

Williams, S. L., AND R. J. ORTH. 1998. Genetic diversity and structure of natural and transplanted eelgrass populations in the Chesapeake Bay. Estuaries 21: 118-128. 